\title{
Echocardiographic and exercise evaluation of results of mitral valvotomy operations
}

\author{
M. F. SHIU, A. CROWTHER, B. S. JENKINS, AND M. M. WEBB-PEPLOE \\ From the Department of Cardiology, St Thomas' Hospital, London
}

SUMMARY M-mode echocardiography was performed in 54 patients 1 month to 3 years after mitral valvotomy for dominant mitral stenosis. The mitral valve closure index (MVCI), an index previously shown to correlate well with the calculated mitral valve area, was used to diagnose residual mitral stenosis. Using the equation MVCI $=33 \mathrm{MVC}-12,12$ patients $(22 \%)$ were deemed to have mild, $4(7 \%)$ moderate, and $2(4 \%)$ severe residual stenosis. Repeat cardiac catheterisation confirmed the diagnosis in 7 patients. The postoperative mitral valve closure index correlated significantly with patients' subjective symptoms and objective exercise indices. It was higher in patients in whom the posterior mitral leaflet movement became normal after valvotomy, and was lower in patients with anterior mitral leaflet excursions below $14 \mathrm{~mm}$ before operation. The mitral valve closure index is a sensitive index for diagnosing residual mitral stenosis after valvotomy.

Residual mitral stenosis accounts for most of the poor results after mitral valvotomy (Baker and Hancock, 1960; Higgs et al., 1970). Clinical diagnosis of residual mitral stenosis is difficult without haemodynamic studies (Selzer and Cohn, 1972). Noninvasive evaluation by echocardiography would be an advantage if the technique could be shown to be reliable. Classical features such as a reduced diastolic closure rate and anterior movement of the posterior mitral leaflet are not sufficiently sensitive to enable diagnosis of lesser degrees of residual mitral stenosis to be made (Cope et al., 1975; Ticzon et al., 1975). We recently reported a new echocardiographic index of mitral valve closure that correlates well with the haemodynamically determined mitral valve area in patients with dominant mitral stenosis (Shiu, 1977). Valvotomy causes an increase in the mitral valve closure index in some, but not all patients. This suggests to us that the postoperative mitral valve closure index may be a simple method for the noninvasive evaluation of residual mitral stenosis. We report here a follow-up echocardiographic study of 54 patients undergoing mitral valvotomy. Echocardiographic analyses included the mitral valve closure index and the pattern of posterior mitral leaflet movement. These features were compared with patients' subjective symptoms, objective exercise indices, and, in 7 patients, postoperative haemodynamic studies.

Received for publication 24 April 1978

\section{Patients and methods}

The study comprised 54 patients, 10 men and 44 women aged from 15 to 64 years, operated on for lone mitral stenosis. Ten patients were in sinus rhythm and the remainder in atrial fibrillation at the time of operation: one patient developed atrial fibrillation after operation. No patient had more than grade 1/4 mitral regurgitation, tricuspid valve disease, or aortic valve disease at the time of preoperative investigation. Ten patients had open valvotomy and 44 patients closed operations using a Tubbs dilator. Ten patients had previously undergone valvotomy.

Postoperative echocardiograms were obtained from one month after operation. Most patients had repeat examinations at yearly intervals, with the longest follow-up period of 3 years. A Smith-Kline Ekoline 20 ultrasonoscope with a $2.25 \mathrm{MHz}$ focused transducer was used and records were made on photographic paper at paper speeds of 50 and $100 \mathrm{~mm} / \mathrm{s}$. The mitral echogram was recorded at a level where both anterior and posterior mitral leaflets were continuously visible and where diastolic leaflet separation was maximal. Classification of anterior and posterior movement of the posterior mitral leaflet in early diastole was as defined by Duchak et al. (1972); in particular, biphasic opening with a net anterior movement was classified as anterior (Popp, 1976). 


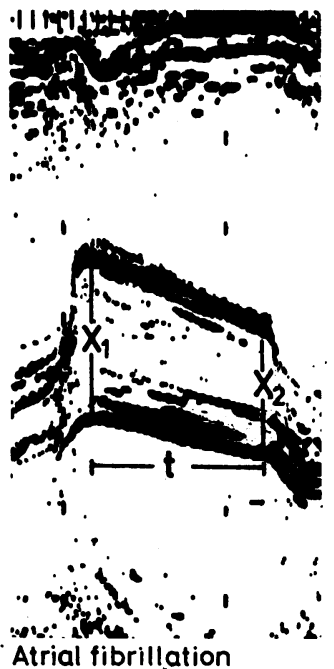

Atrial fibrillation
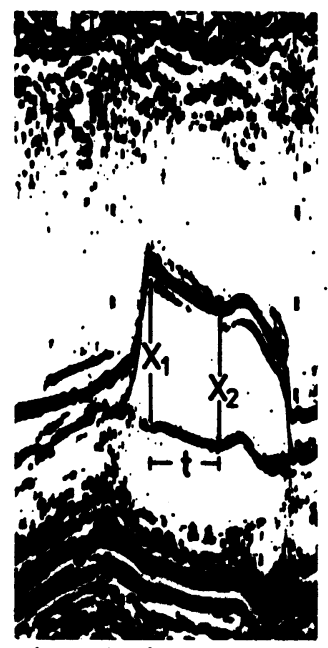

Sinus rhythm

Fig. 1 Mitral echograms from a patient in atrial fibrillation and in sinus rhythm, showing the measurements of early and late diastolic separations $\left(X_{1}\right.$ and $\left.X_{2}\right)$ of the anterior and posterior mitral leaflets. Mitral valve closure index $(M V C I)=\frac{X_{1}-X_{2}}{X_{1} \times t} \times 100$

where $t$ is time in seconds.

The mitral valve closure index (MVCI) was calculated using the equation MVCI $=\frac{X_{1}-X_{2}}{X_{1} \times t}$ $\times 100$ per cent where $X_{1}$ and $X_{2}$ are the early and late diastolic separations of the anterior and posterior mitral leaflet echoes, and ' $t$ ' the time in seconds between the two measurements (Fig. 1). Mitral echograms not showing both mitral leaflets throughout diastole were rejected, as were those with diastolic intervals shorter than $200 \mathrm{~ms}$. Where leaflet closure stopped before end-diastole, such as during long diastolic intervals, $\mathrm{X}_{\mathbf{2}}$ was measured at the time leaflet closure ceased (Fig. 2).

Symptomatic grading (New York Heart Association Classification) and exercise testing were done at least 3 months after operation. Measurements of mitral valve closure index nearest to the third postoperative month were taken for comparison with symptoms and exercise tests.

Exercise tests were performed on a bicycle ergometer using a standard multistaged regimen. Thirty-three patients were exercised to a satisfactory end point of either dyspnoea or fatigue. Maximum exercise capacity was defined as the highest work load (in kilopond metres per min) sustained for 2 minutes. Patients were then rested and 19 patients
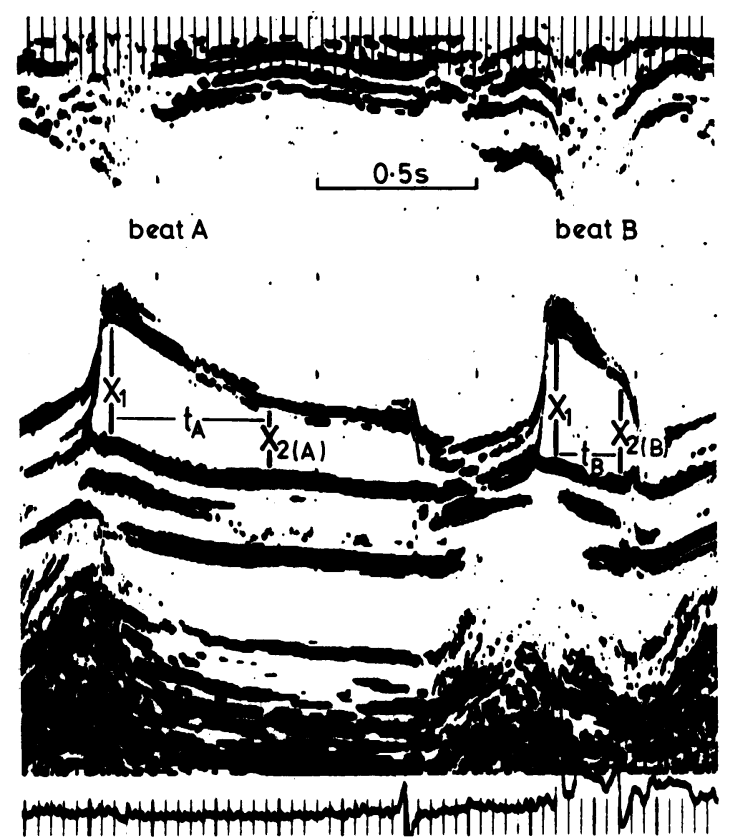

Fig. 2 Measurement of mitral valve closure index (MVCI) in beats of long diastolic intervals. In beat $A$ diastolic approximation of the anterior and posterior mitral leaflets has ceased before end-diastole, at $X_{2}(A)$. The mitral valve closure index (MVCI) calculated as $\frac{X_{1}-X_{2}}{X_{1} \times t A}(A)$ is similar to that of $\frac{X_{1}-X_{2}}{X_{1} \times t B}(B)$.

performed submaximal exercise for 4 minutes with collection of expired air during the last minute. On and off line gas analysis using a Mass Spectrometer (20th Century Electronics Ltd.) and an electronic spirometer (Mercury Electronics Ltd. CS6) allowed estimation of oxygen uptake and cardiac output during submaximal exercise. The exercise tests were conducted by one of us (A.C.) with no knowledge of the patients' symptomatic grading or echocardiographic results.

\section{REPEAT HAEMODYNAMIC STUDIES}

Postoperative cardiac catheterisation was performed in 7 patients 1 to 3 years after valvotomy. The reason for repeat study was persistent symptoms of dyspnoea in 6 patients, and recent onset angina in the seventh. All patients had left and right heart catheterisation including direct left atrial pressure measurements by transseptal pucture. Mitral valve areas were calculated from the mean diastolic mitral gradient using direct left atrial and left ventricular pressures, and cardiac output using duplicate dye dilution curves (Gorlin and Gorlin, 1951). 


\section{Results}

\section{POSTOPERATIVE MITRAL VALVE CLOSURE \\ INDEX}

The postoperative mitral valve closure index (MVCI) in the 54 patients studied ranged from 0 to $180(90 \pm 6)$, and was below 70 in 18 patients. Using the regression equation $\mathrm{MVCI}=33 \times$ MVA - 12 (Shiu, 1977), these 18 patients were deemed to have residual mitral stenosis with estimated mitral valve areas below $2.5 \mathrm{~cm}^{2}$. These patients were further subdivided according to their postoperative mitral valve closure index, using the ranges 0 to 30,31 to 50,51 to 70 to represent the respective mitral valve areas of $<1.3 \mathrm{~cm}^{2}, 1.3$ to $1.7 \mathrm{~cm}^{2}$, and 1.8 to $2.5 \mathrm{~cm}^{2}$. By this method, 12 $(22 \%)$ patients had mild, $4(7 \%)$ moderate, and 2 (4\%) severe residual stenosis (Fig. 3 ).

\section{FUNCTIONAL CLASS}

The distribution of the postoperative mitral valve closure indices according to functional class is shown in Fig. 4. Twenty-one patients were asymptomatic (Class 1) and their mean mitral valve closure index $(110 \pm 6)$ was significantly higher than patients with residual symptoms $(P<0.005)$. Twenty-five patients were in functional class II and 6 were in class III (mean closure index $75 \pm 6$ and $50 \pm 11$, respectively). Two patients left the country before evaluation at 3 months and were not included.

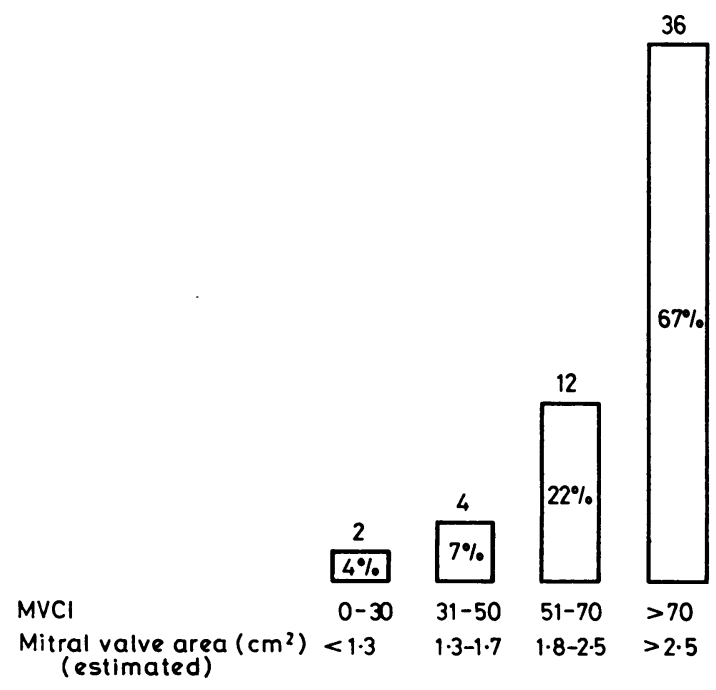

Fig. 3 Incidence of various degrees of residual mitral stenosis as shown by the distribution of the postoperative mitral valve closure index (MVCI) in 54 patients. The mitral valve areas were estimated using the regression equation $M V C I=33, M V A=12$ (Shiu, 1977).

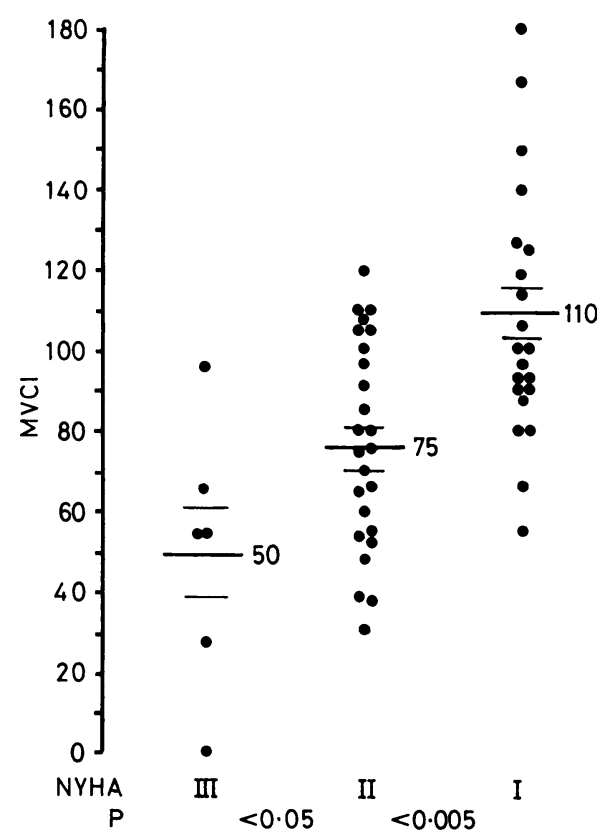

Fig. 4 Distribution of postoperative mitral valve closure index (MVCI) in 52 patients according to postoperative symptoms. Though the mean MVCIs are significantly different for each group, considerable overlap between the groups reflects the poor correlation between symptoms and residual mitral stenosis.

\section{EXERCISE INDICES}

Patients with low postoperative mitral valve closure indices performed worse in the exercise tests. Maximum work-load correlated significantly with the postoperative mitral valve closure index in both

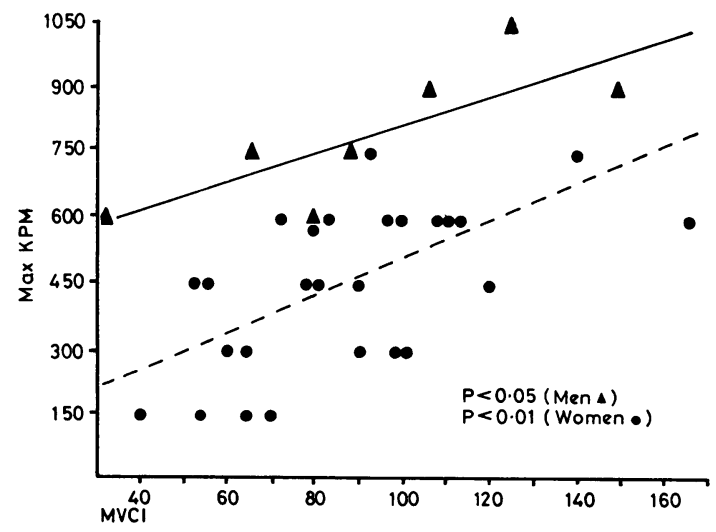

Fig. 5 Correlation between maximum exercise capacity (in kilopond metres/min) and postoperative mitral valve closure index (MVCI) in 33 patients. As expected, male patients had higher exercise capacities than female patients given the same MVCI. 


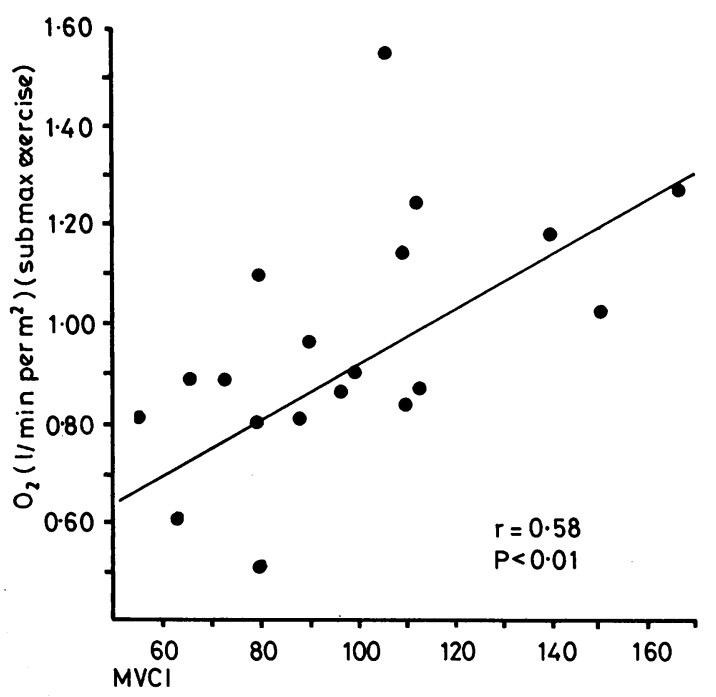

Fig. 6 Correlation between oxygen uptake during submaximal exercise and postoperative mitral valve closure index (MVCI) in 19 patients.

men and women $(P<0.05$ for men; $P<0.01$ for women; Fig. 5). As might be expected, in patients with comparable mitral valve closure indices, male patients achieved higher maximum work loads than female patients.

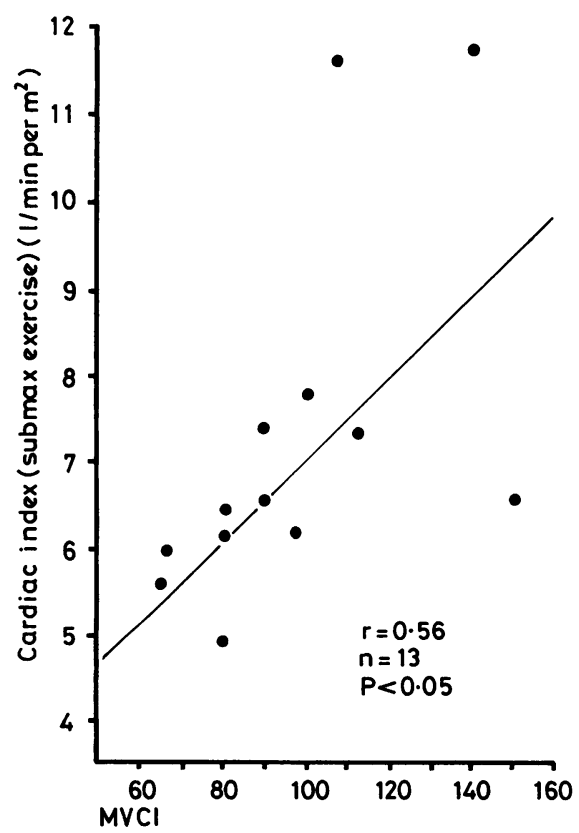

Fig. 7 Correlation between cardiac index during submaximal exercise and postoperative mitral valve closure index (MVCI) in 13 patients.
Difficulties with expired air collection during submaximal exercise reduced the number of patients to 19 for oxygen uptake and 13 for cardiac index measurements. Again, patients with higher postoperative levels achieved significantly higher oxygen uptake and cardiac indices during submaximal exercise $(P<0.01$ and $P<0.05$, respectively. Fig. 6 and 7).

\section{REPEAT HAEMODYNAMIC STUDIES}

Fig. 8 shows the haemodynamic and echocardiographic findings in the 7 patients who had repeat cardiac catheterisation after valvotomy. In the 2 patients with a postoperative mitral valve closure index lower than 30 severe stenosis was confirmed. One of them subsequently had a mitral valve replacement; the other was considered too high a risk on other grounds for further operation. Two patients with mitral valve closure indices over 90 had no residual stenosis. Though the number was small, the correlation between mitral valve closure index and mitral valve area appeared unchanged after valvotomy.

\section{POSTERIOR MITRAL LEAFLET MOVEMENT}

BEFORE AND AFTER VALVOTOMY

Analysis of echocardiographic posterior mitral leaflet movement before valvotomy in 45 patients showed anterior movement in $38(84 \%)$ and posterior movement in $7(16 \%)$. Abnormal anterior movement remained after valvotomy in 18 patients, and the movement became posterior in 20 (Fig. 9).

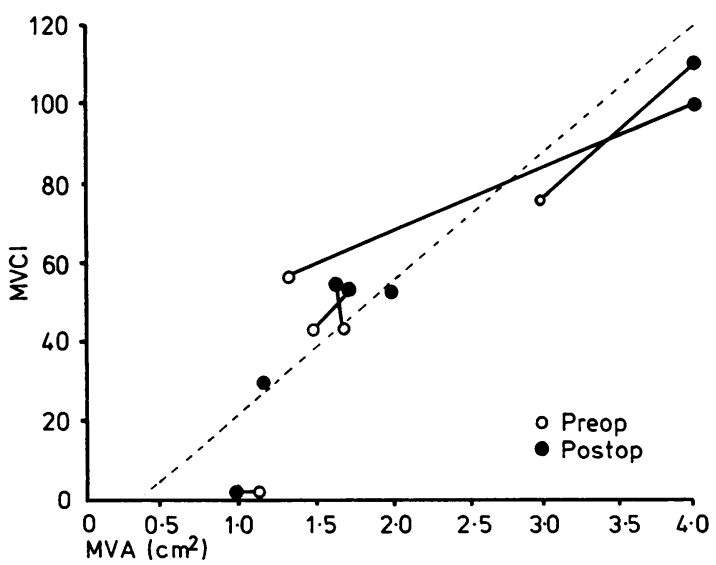

Fig. 8 Correlation between mitral valve closure index (MVCI) and calculated mitral valve area from haemodynamic data in 7 patients investigated after valvotomy operations (black dots). Five of the 7 patients also had preoperative measurements of both (circles). The dotted line is the regression line between $M V C I$ and mitral valve area in 40 patients before valvotomy. 


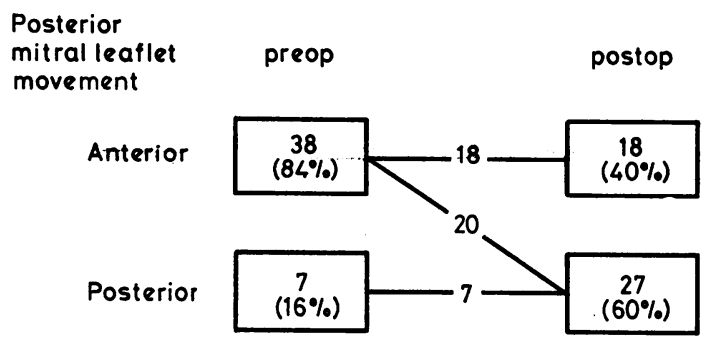

Fig. 9 Early diastolic movement of the posterior mitral leaflet in 45 patients before and after valvotomy. Of the 38 patients with anterior posterior mitral leaflet movement before surgery, 18 showed no change and 20 showed normal posterior movement afterwards.

Patients with posterior mitral leaflet movement before valvotomy showed no change.

In Fig. 10, 42 of these patients were divided into 3 groups according to their posterior mitral leaflet movement before and after valvotomy. The postoperative mitral valve closure index was highest in the group in whom posterior mitral leaflet movement was anterior before operation but posterior afterwards $(108 \pm 7, \mathrm{P}<0.001)$. The lowest postoperative mitral valve closure indices were found in those patients whose posterior mitral leaflet re-

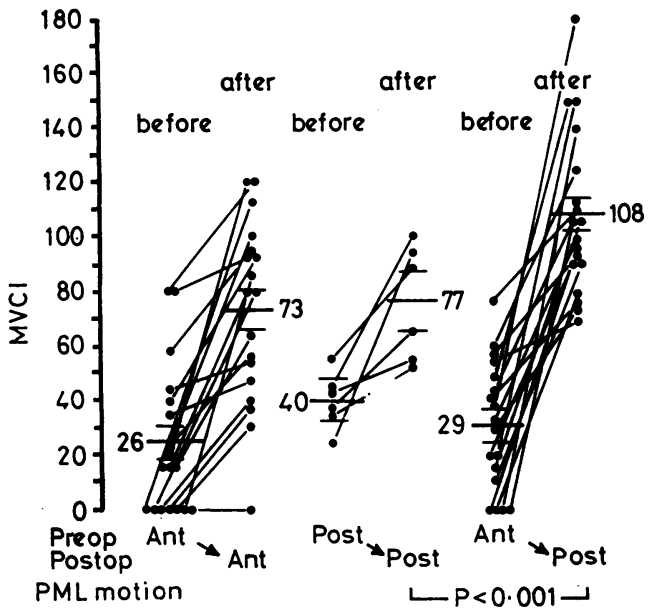

Fig. 10 Pre-and postoperative mitral valve closure index (MVCI) in 43 patients grouped according to posterior mitral leaflet motion before and after valvotomy. The change in mean mitral valve closure index (MVCI) (shown with SEM) for each group is shown. Patients in whom posterior mitral (PML) movement became normal as a result of the operation had significantly higher postoperative MVCI than the rest. Patients in whom PML movement was posterior before operation had the smallest increase in mean MVCI.

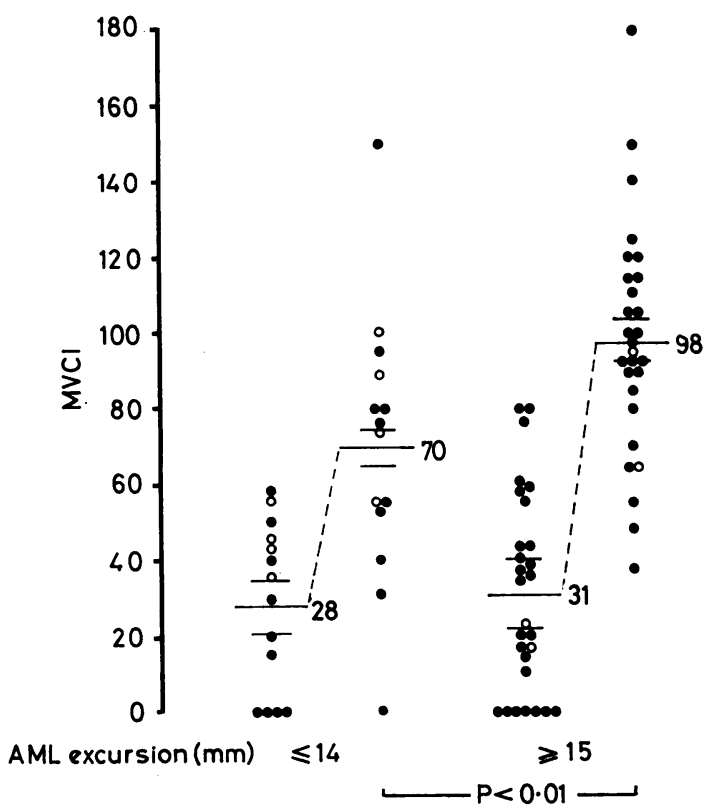

Fig. 11 Pre-and postoperative mitral valve closure index (MVCI) in 42 patients grouped according to whether anterior mitral leaflet (AML) excursion was greater or less than $14 \mathrm{~mm}$. Mean and SEM are shown. Despite similar preoperative MVCI, patients with lower postoperative anterior mitral leaflet $(A M L)$ excursions had significantly lower MVCI. Open circles represent patients who also had normal posterior mitral leaflet movement before valvotomy.

mained anterior after operation $(73 \pm 8)$. Though patients with normal posterior mitral leaflet movement had the highest preoperative mitral valve closure index $(40 \pm 10)$, their postoperative mitral valve closure indices $(77 \pm 11)$ were not significantly higher than those patients who had persistently anterior posterior mitral leaflet movement after operation.

\section{PREOPERATIVE ANTERIOR MITRAL LEAFLET EXCURSION}

In the 42 patients for whom preoperative ecnocardiograms were available, 14 had anterior mitral leaflet excursions below $14 \mathrm{~mm}$ and their postoperative mitral valve closure indices were significantly lower than the rest $(70 \pm 7$ and $98 \pm 6$, respectively, $P<0.01$, Fig. 11). Four patients with abnormally low excursions also had posterior diastolic movement of the posterior mitral leaflet.

\section{Discussion}

Lasting haemodynamic and symptomatic improvement after mitral valvotomy depends on adequate 
relief of the mitral obstruction (Ellis et al., 1959; Baker and Hancock, 1960). The true incidence of residual stenosis after mitral valvotomy may be higher than suspected on clinical grounds (Selzer and Cohn, 1972). Feigenbaum et al. (1968) and Higgs et al. (1970) showed that persistence of symptoms or their return after a period of apparent improvement was most often the result of residual stenosis and not mitral regurgitation or restenosis. In Feigenbaum et al.'s (1968) study, pre- and postoperative investigations showed that the change in the mitral valve area varied from $-0.1 \mathrm{~cm}^{2}$ to $+3.8 \mathrm{~cm}^{2}$. Similarly, Mullin et al. (1972) found that the postoperative mitral valve area in 12 patients ranged from $1.4 \mathrm{~cm}^{2}$ to $3.6 \mathrm{~cm}^{2}$.

Routine echocardiographic examination of patients after mitral valvotomy would disclose more patients with residual mitral stenosis than suspected clinically. The classical echocardiographic criteria for mitral stenosis are a slow diastolic closure rate and anterior movement of the posterior mitral leaflet. Neither of these features is sufficiently sensitive to allow confident diagnosis of residual stenosis. The diastolic closure rate has been shown to increase after valvotomy (Edler, 1967) but more recent studies showed that this measurement correlated poorly with valve area as determined haemodynamically (Cope et al., 1975; Nichol et al., 1977;
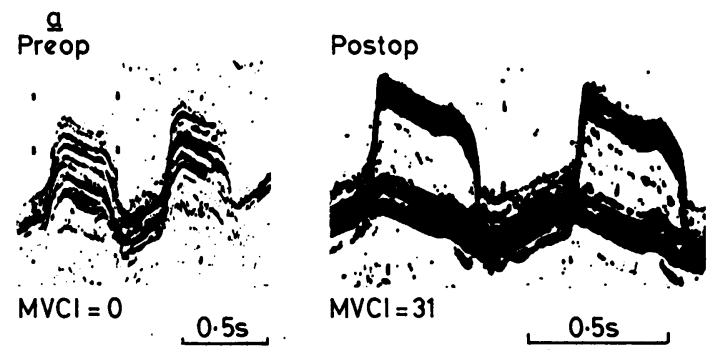

$$
\text { b }
$$
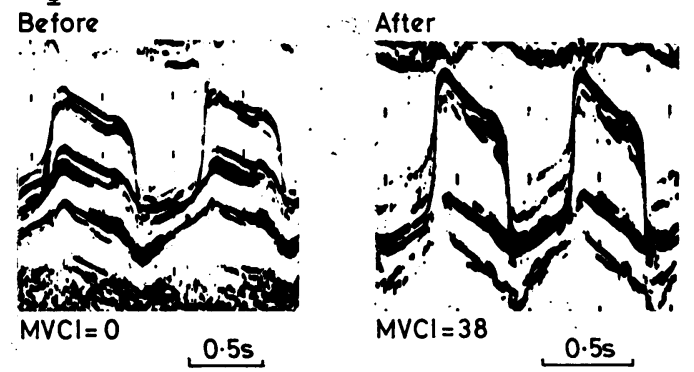

Fig. 12 Pre-and postoperative mitral echograms in 2 patients in whom posterior mitral leaflet movement remained anterior after valvotomy. The postoperative mitral valve closure index (MVCI) of both patients is in the moderate to severe stenosis range.
Shiu, 1977). 'Normal' posterior movement of the posterior mitral leaflet has been reported in up to 17 per cent of patients with true and sometimes severe mitral stenosis so that posterior mitral leaflet movement alone cannot be relied on to diagnose residual stenosis.

The rationale behind the measurement of mitral valve closure index is that mitral valve closure is delayed in mitral stenosis proportionate to the severity of the obstruction. The fundamental difference between the mitral valve closure index
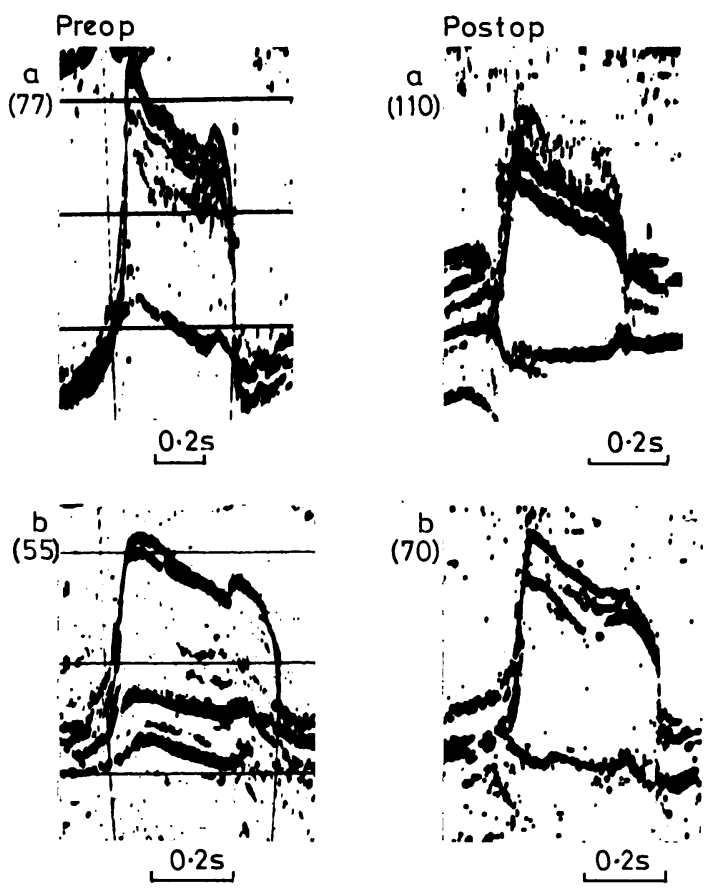

(15)
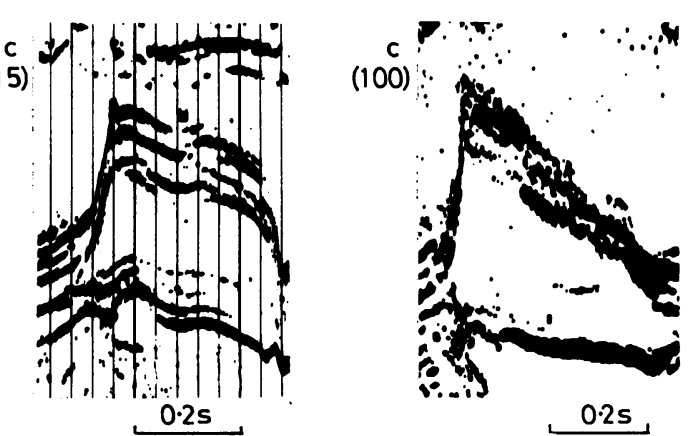

Fig. 13 Pre-and postoperative mitral echograms in 3 patients in whom posterior mitral leaflet movement became normal after valvotomy. Numbers in brackets are the mitral valve closure index (MVCI). No patient showing such a change had a postoperative MVCI below 70 . 
and the diastolic closure rate is that the mitral valve closure index measures the intrinsic rate of closure of the two mitral leaflets while the diastolic closure rate measures anterior mitral leaflet movement plus mitral ring and other movements not relevant to valve closure. The relation between mitral valve closure index and haemodynamically determined mitral valve area found in preoperative patients would be expected to remain after mitral valvotomy, since residual mitral stenosis will again cause delayed valve closure.

We have chosen an arbitrary postoperative mitral valve closure index of 70 below which we consider that residual stenosis is present. From the previous study in preoperative patients, this value is equivalent to a mitral valve area of $2.5 \mathrm{~cm}^{2}$. By this criterion, one-third of our patients have residual stenosis. Of these 18 patients, 12 had mild, 4 moderate, and 2 severe stenosis as judged from their mitral valve closure index. Seven patients -5 with residual mitral stenosis and 2 without-had haemodynamically determined mitral valve areas in close agreement with that estimated by their mitral valve closure index.

The postoperative mitral valve closure indices were significantly different in patients of different functional classes (Fig. 4). Even more importantly, patients with higher postoperative mitral valve closure index achieved higher maximum exercise levels and had higher oxygen uptake and cardiac indices during submaximal exercise. While factors such as patient co-operation, left ventricular function, and mitral regurgitation may influence results of exercise tests, it is likely that residual mitral stenosis is the major limiting factor in these patients. Certainly Feigenbaum et al. (1968) showed that increases in cardiac index and falls in pulmonary vascular resistance correlated closely with increases in valve areas.

A change from anterior to posterior movement of the posterior mitral leaflet has been taken to indicate a successful valvotomy (Feigenbaum, 1976). In this study, those patients in whom the posterior mitral leaflet remained anterior after valvotomy had a significantly lower postoperative mitral valve closure index than those in whom posterior mitral leaflet movement became normal (Fig. 11, 12, and 13). Residual stenosis, as defined by a postoperative mitral valve closure index of below 70, was not seen in any of the patients in whom posterior mitral leaflet movement became normal, but was found in 50 per cent of patients in whom anterior posterior mitral leaflet persisted.

Two features in the preoperative echocardiogram were found to be associated with an increased incidence of residual mitral stenosis. These are an anterior mitral leaflet excursion of below $14 \mathrm{~mm}$, and posterior diastolic movement of the posterior mitral leaflet. Low anterior mitral leaflet excursion has been known to be a relative contraindication for mitral valvotomy (Nanda et al., 1975). The other finding was less expected, but supports the concept that normal posterior mitral leaflet movement, despite the presence of significant mitral stenosis,
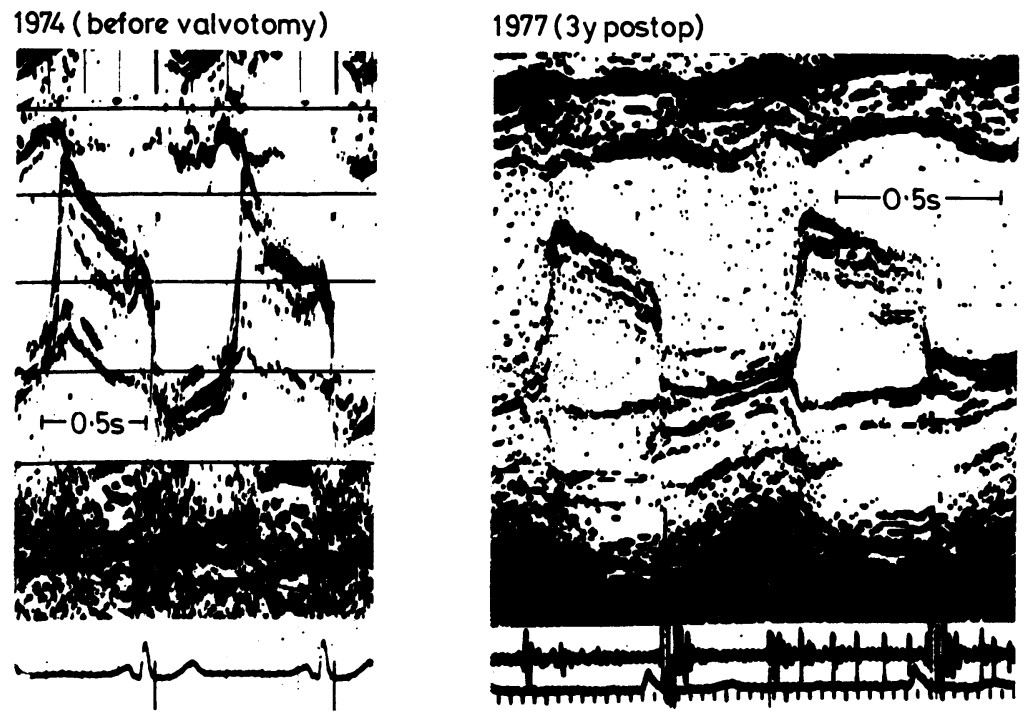

Fig. 14 Pre-and postoperative echocardiograms in a patient followed up for 3 years. Normal posterior mitral leaflet movement persisted from the time of valvotomy. 
denotes cuspal rather than commissural disease (Ticzon et al., 1975; Shiu et al., 1978), and thus will not be improved by mitral valvotomy.

None of our patients showed a significant reduction in the mitral valve closure index or change in posterior mitral leaflet movement on repeated examination after valvotomy (Fig. 14). Longitudinal studies over a longer period may show such changes and throw light on the incidence of mitral restenosis and on whether restenosis is commonly the result of commissural refusion or progressive cuspal disease.

\section{References}

Baker, C., and Hancock, E. W. (1960). Deterioration after mitral valvotomy. British Heart fournal, 22, 281-294.

Cope, G. D., Kisslo, J. A., Johnson, M. L., and Behar, V. S. (1975). A reassessment of the echocardiograph in mitral stenosis. Circulation, 52, 664-670.

Duchak, J. M., Chang, S., and Feigenbaum, H. (1972). The posterior mitral valve echo and the echocardiographic diagnosis of mitral stenosis. American fournal of Cardiology, 29, 628-632.

Edler, I. (1967). Ultrasoundcardiography in mitral valve stenosis. American fournal of Cardiology, 19, 18-31.

Ellis, L. B., Harken, D. E., and Black, M. (1959). Clinical study of 1000 consecutive cases of mitral stenosis two to nine years after mitral valvuloplasty. Circulation, 19, 803-820.

Feigenbaum, H. (1976). Echocardiography, 2nd ed., Chapter 4, Figure 4-24. Lea and Febiger, Philadelphia.

Feigenbaum, H., Linback, R. E., and Nasser, W. K. (1968). Hemodynamic studies before and after instrumental mitral commissurotomy. Circulation, 38, 261-276.
Gorlin, R., and Gorling, S. G. (1951). Hydraulic formula for calculation of area of the stenotic mitral valve, other cardiac valves and central circulatory shunts. American Heart fournal, 41, 1-29.

Higgs, L. M., Glancy, D. L., O’Brien, K. P., Epstein, S. E., and Morrow, A. G. (1970). Mitral re-stenosis : an uncommon cause of recurrent symptoms following mitral commissmotomy. American fournal of Cardiology, 26, 34-37.

Mullin, E. M., Jr., Glancy, D. L., Higgs, L. M., Epstein, S. F., and Morrow, A. G. (1972). Current results of operations for mitral stenosis. Circulation, 46, 298-308.

Nanda, N. C., Gramiak, R., Shah, P. M., and DeWelse, J. A. (1975). Mitral commissurotomy versus replacement-preoperative evaluation by echocardiography. Circulation, 51, 263-267.

Nichol, P. M., Gilbert, B. W., and Kisslo, J. A. (1977). Twodimensional echocardiographic assessment of mitral stenosis. Circulation, 55, 120-128.

Popp, R. L. (1976). Echocardiographic assessment of cardiac disease. Circulation, 54, 538-552.

Selzer, A., and Cohn, K. E. (1972). Natural history of mitral stenosis. A review. Circulation, 45, 878-890.

Shiu, M. F. (1977). Mitral valve closure index. Echocardiographic index of severity of mitral stenosis. British Heart Fournal, 39, 839-843.

Shiu, M. F., Jenkins, B. S., and Webb-Peploe, M. M. (1978). Echocardiographic analysis of posterior mitral leaflet movement in mitral stenosis. British Heart fournal, 40, 372-376.

Ticzon, A. R., Damato, A. N., Caracta, A. R., Law, S. H., and Gross, L. (1975). Echocardiographic manifestation of 'false' mitral stenosis that was. Annals of Internal Medicine, 83, 503-505.

Requests for reprints to Dr M. F. Shiu, Department of Cardiology, St Thomas' Hospital, London SE1 7EH. 